\title{
Increased risk of cancer among relatives of patients with lung
} cancer in China

\author{
Yongtang Jin*1, Yingchun $\mathrm{Xu}^{1}$, Ming $\mathrm{Xu}^{2}$ and Saoli $\mathrm{Xu}^{3}$
}

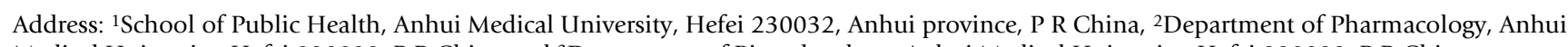
Medical University, Hefei 230032, P R China and 3Department of Biotechnology, Anhui Medical University, Hefei 230032, P R China

Email: Yongtang Jin* - jinedu@163.com; Yingchun Xu - ycxu66@163.com; Ming Xu - mingxu@ah172.com.cn; Saoli Xue - xuesl@sina.com

* Corresponding author

Published: II November 2005

BMC Cancer 2005, 5:146 doi:10.1 |86/147|-2407-5-146
Received: 17 July 2005

Accepted: II November 2005

This article is available from: http://www.biomedcentral.com/I47/-2407/5//46

(C) 2005 Jin et al; licensee BioMed Central Ltd.

This is an Open Access article distributed under the terms of the Creative Commons Attribution License (http://creativecommons.org/licenses/by/2.0), which permits unrestricted use, distribution, and reproduction in any medium, provided the original work is properly cited.

\begin{abstract}
Background: Genetic factors were considered as one of the risk factors for lung cancer or other cancers. The aim of this work was to determine whether a genetic predisposition accounts for such familial aggregation of cancer among relatives of lung cancer probands.
\end{abstract}

Methods: A case-control study was conducted in 800 case families identified by lung cancer patients (probands), and in 800 control families identified by the probands'spouses. The data were analysed with logistic regression analysis model.

Results: The data revealed a significantly greater overall risk of cancer $(O R=1.82, P<0.01)$ in the proband group. The relatives of lung cancer probands maintained an increased risk of non-lung cancer $(P<0.05)$ after adjusting for confounder factors. The crude odds ratio of a proband family having one family member with cancer was 1.67 compared with control families. Proband families were 2.56 times more likely to have two other family members with cancer. For three cancers and four or more cancers, the risk increased to 3.50 and 5.91, respectively. The most striking differences in cancer prevalence between proband and control families were noted for cancer risk among female relatives. The strongest effects were for not only lung cancer in any female relatives (OR 2.17, 95\% Cl I.60-3.64) and mothers (OR 2.78, 95\% Cl I.23-5.12) and sisters (OR 2.03, 95\% Cl

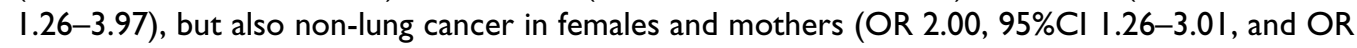
$2.34,95 \% \mathrm{Cl}$ I.28-4.40, respectively).

Conclusion: These data support the hypothesis of a genetic susceptibility to cancer in families with lung cancer, and the female genetic susceptibility to cancer might be greater than male.

\section{Background}

Inasmuch as some 22 per cent of all persons die of cancers affecting various anatomic sites, the random occurrence of cancer among several members of a nuclear family would be usual [1]. However, when cancers occur among members in several generations of the same family, chance itself may not be sufficient to account for that occurrence.
An increased familial risk for cancer and particularly lung cancer has been demonstrated among relatives of lung cancer patients [2-6]. However, the precise genetic characteristics which influence lung cancer susceptibility are not known. Many studies of families may be used to attempt to disentangle the effects of shared environmental risk factors and genetic factors [7-9]. 
However, these conclusions do not address the occasionally observed increased frequency of cancers of several sites in combination, such as those of the breast, brain, bone, liver, adrenal cortex, blood, and/or lymphatics[2]. Warthin[10] was the first to describe a large kindred having a remarkable high incidence of cancers at various sites. Pedigree analysis of several large families with multiple cancers across several generations led Lynch and Krush[11] to propose a new genetic entity, later called "cancer family syndrome". In general, those studies showed that the familial occurrence of cancer tends to deviate from the Possion distribution, in that more families than expected by chance have two or more affected, closely related members. However, these high-risk families were selected for study because of their high frequency of cancer cases. Because the laws of probability can not preclude the probability that these cancer families merely represent a chance occurrence, some investigators have questioned genetic susceptibility as a basis for familial aggregation of cancers at various sites.

To explore whether familial aggregation of cancer represents a random or specific event, we conducted a retrospective case-control study of families. The lung cancer patient (proband) was used to identify a case family and the proband's spouse was used to identify a control family in rural regions of Anhui, China.

\section{Methods}

\section{Study population}

Case-probands were selected if they satisfied a defined eligibility criteria, namely: all farmers who had died of a primary malignancy of the lung (stated as an underlying cause of death in their death records) in three counties in Anhui over a ten-year period (1995-2004). Spouses of probands were included in the control group if these spouses were themselves unaffected with lung cancer and were farmers. The families of probands and controls have lived in rural regions for over 20-year.

The population of the rural regions in Anhui had almost little migration 20 years ago and the cultural patterns and ethnicity have retained definite demographic characteristics. The use of spouse-matched controls can be expected to control for the potential confouning effects of different cultural and residential environment, e.g. diet, drinking water, socioeconomic status and so on.

First-degree relatives (parents, full siblings) of probands were designated as case families. The control families comprised first-degree relatives (parents, full siblings) of the spouses of probands. Thus, in the following sections of this paper, the term "family", when applied to the study population, never includes the proband or spouse.

\section{Data collection}

A complete listing of all deaths satisfying the eligibility criteria was obtained from the local Tumor Prevention and Treatment Office of Health Bureau in rural area. Standard demographic characteristics of the probands and the identities of their next-of-kin were obtained from the death records of probands. Local community doctors were recruited to help initiate contact with family members of the case-proband. Provided with the identity of the proband's next-of-kin as well as the usual address of the deceased, the doctors generated a list of addresses of all family members in each pedigree.

Trained interviewers with standard protocols obtained information on each member of the family by face-to-face interviews from (in order of preference) the involved persons (except the proband or other deceased family member), spouse, parent, sibling, or adult offspring. Cancer histories were verified by two methods: 1) a review of death certificates on a sample (90.4 and 88.4 percent, respectively) of relatives of probands and spouses who were reported to have died in rural regions of Anhui and 2) corroborative information from additional family contacts. Because only first-degree relatives (parent and siblings) were included in the study, bias introduced by inability to verify all cancer deaths should be minimal[12].

For the protection of human subjects, all of the subjects in this study signed a consent form according to the guidelines of the World Medical Association Declaration of Helsinki.

\section{Data analysis}

Frequency statistics of the study population were computed. Mean age differences between proband and spouse relatives were tested for signficance using two-sided t tests. To determine whether the distribution of relatives was equivalent between study groups, contingency table chisquare tests were used. for each family, design variables were assigned as 1 for the presence and 0 for the absence of each of the following among the proband's or spouse's relatives: one, two, three, four or more cancers. Logistic regression analysis was used to the data to predict whether a family belonged to the case or control group based on these design variables. The resulting regression coefficients $\left(\beta_{\mathrm{i}}\right)$ were used to calculate the relative risks of cancer by the formula: odd ratio $=e^{\beta i}$, for the ith variables. To determine whether differences in environmental exposure between the case an control families could explain the difference in cancer occurrence, another logistic model was fitted to predict cancer occurrence in each family member based on age, sex, the occupation/industrial exposure pack-years of tobacco exposure and a variable that expressed family membership (case or control). Because 
Table I: Characteristics of probands' and spouses' families

\begin{tabular}{|c|c|c|c|c|}
\hline $\begin{array}{l}\text { Family members and } \\
\text { characteristic }\end{array}$ & Proband No. (\%) & Mean age, yr, of proband & Spouse No. (\%) & Mean age, $y r$, of spouse \\
\hline Families & 800 & & 800 & \\
\hline All relatives & 4,453 & & 4,378 & \\
\hline Male relatives & $2,484(100.0)$ & & $2,418(100.0)$ & \\
\hline Living & $\mathrm{I}, 043(42.0)$ & 56.0 & $1,064(44.0)$ & 55.3 \\
\hline Dead & $\mathrm{I}, 44 \mathrm{I}(58.0)$ & 49.9 & $1,354(56.0)$ & 59.4 \\
\hline Female relatives & $1,969(100.0)$ & & $1,960(100.0)$ & \\
\hline Living & $650(33.0)$ & 57.7 & $784(40.0)$ & 60.0 \\
\hline Dead & $1,319(67.0)$ & 51.0 & $1,176(60.0)$ & 57.9 \\
\hline Parents & $1600(100.0)$ & & $1600(100.0)$ & \\
\hline Livinga & $128(8.0)$ & 66.8 & $192(12.0)$ & 69.0 \\
\hline Dead & $1,472(92.0)$ & 60.5 & $1,408(88.0)$ & 63.1 \\
\hline Siblings & $2,853(100.0)$ & & $2,778(100.0)$ & \\
\hline Living & $\mathrm{I}, 883(66.0)$ & 49.0 & $\mathrm{I}, 972(71.0)$ & 50.8 \\
\hline Dead & $970(34.0)$ & 46.2 & $806(29.0)$ & 49.0 \\
\hline
\end{tabular}

a $\mathrm{P}<0.0$ I, between proportion of relatives in proband and spouse groups who were parents.

the excess risk of cancer in the proband families remained statistically significant, a test of homogeneity was performed to determine whether the study groups differed in their distribution of cancer types. To isolate where these differences occurred, contingency chisquare tests were applied.

Crude odds ratios (OR) were calculated as estimates of the relative risks, and Woolf's method was used to determine 95\% confidence intervals (CI)[13]. Maximum likelihood estimates of adjusted ORs were obtained from unconditional logistic regression analysis by the PHREG procedure in SAS software[14].

These variables examined as possible confounders and effect modifiers included: number of first-degree relatives $(2-4,5-7,8-10,>10)$; smoking status (never, ex-smoker, current smoker); smoking duration (never, 1-29 yr, 30$45 \mathrm{yr},>45 \mathrm{yr}$ ); amount smoked (none, $<20$ cigarettes per day (cpd), $20-30 \mathrm{cpd}, 31-40 \mathrm{cpd},>40 \mathrm{cpd}$ ); pack-years (defined as cigarette packs smoked daily multiplied by years of smoking, gram equivalents of leaf tobacco. Assuming $1 \mathrm{~g}$ per cigarette) of smoking (none, $>0-20$, $>20-40,>40$ pack-years); residence (females only) (selected three counties vs other counties); age $(<55 \mathrm{yr}$, 55-65 yr, >65 yr); ethnicity (Han vs others); sex, passive smoking exposure (ever/never and by total years); education (through high school vs greater than high school and by level: none, primary school, middle school, high school, >high school); martital status (never married, married, and widowed, divorced or separated); high-risk industry/occupation (employed in jobs with exposure to asbestos, benzene, beryllium, bischloromethyl ether, ceramic dust, talc, chemical fertilizers, chromium or chro- mates, coke oven emissions, dyes, glues, lacquers, fiberglass, cotton dust, insecticides, pesticides, herbicides, fungicides, isopropyl oil, paint sprays, petroleum products, radioactive materials, vinylchloride or explosives); the cumulative exposure to smoky coal use for a given individual was determined by multiplying the annual rate of smoky coal use times the number of years (coal consumption was generally fixed for the households over the life cycle of the family and three exposure categories were formed: $>0-70,70-140$, and $>140$ tons); alcohol consumption (ever/never); vital status; and type of respondent (self/spouse/other); history of COPD (yes/no).

\section{Results}

In our study, 800 eligible probands were identified. These families were only included in the data set once (if there are more than one cases in a family, the earliest case diagnosed was selected as the proband). An average of 2.6 and 2.9 interviews (contacts) were made to complete information on each of these proband and spouse families, respectively. The largest proportion of the contacts was through siblings, followed closely by spouses. Less than 17 per cent of the contacts were from adult offspring and surviving parents. The distributions of reported cancer in relatives by source of contacts were not significantly different between proband and spouse families. Information on complete two-generation pedigrees was obtained for 800 case families and 800 control families. The remaining families of probands and spouses were excluded from the analysis because of: inadequate information in names, addresses, incomplete data on each individual in the pedigree (2.8 per cent), or refusals to participate ( 4.2 per cent). The resulting sample includes 4,453 case family members and 4,378 control family members. 
Table 2: Familial risk of developing cancer (all sites) among lung cancer case families and control families

\begin{tabular}{|c|c|c|c|c|c|c|c|}
\hline \multirow[b]{2}{*}{ Cancers (no.) } & \multicolumn{3}{|c|}{ Case } & \multicolumn{3}{|c|}{ Control } & \multirow[b]{2}{*}{$\mathrm{OR}^{\mathrm{c}}(95 \% \mathrm{Cl})$} \\
\hline & Families (no.) & Relatives $^{\mathrm{a}}$ (no.) & $\mathrm{Age}^{\mathrm{b}}(\mathrm{M})$ & Families (no.) & Relatives $^{\mathrm{a}}$ (no.) & $\mathrm{Age}^{\mathrm{b}}(\mathrm{M})$ & \\
\hline 0 & 518 & 2369 & & 627 & 2598 & & \\
\hline 1 & 209 & 902 & 62.2 & 143 & 814 & 61.8 & $1.67 * *(1.22-2.01)$ \\
\hline 2 & 51 & 251 & 61.0 & 22 & 112 & 60.2 & $2.56 * *(1.44-4.29)$ \\
\hline 3 & 21 & 95 & 62.2 & 7 & 37 & 63.1 & $3.50 * *(1.36-10.02)$ \\
\hline $4+$ & 4 & 36 & 62.4 & I & 17 & 63.2 & $5.91(0.79-132.10)$ \\
\hline
\end{tabular}

** $\mathrm{p}<0.01$

a Excludes probands and spouses.

b Mean age of members living with or deceased from cancer.

c Represents familial risk of case families, not individual risk, after adjusting for family size, total smoky coal exposure, number of person smoking and commune of residence.

A total of 390 case family members(8.76 per cent) and 212 control family members ( 4.84 per cent) were reported to have cancer (only primary malignancy counted). 36 (9.2 per cent) and 22 (10.4 per cent) were living cancer cases in the case and control groups, respectively. Of the cancer deaths reported in the death certificates, 92.8 per cent were detected by interview. Analogously, 94.2 per cent of the noncancer deaths were reported. There were no significant differences in age at death or age of living family members with cancer between the two study groups.

Male probands almost numbered equally female probands by a ratio of 1.12 to 1.05 . The mean family size was similar for both groups, 5.6 including the proband, and 5.5 including the spouse, respectively. Although more of the probands were male and more were older than their spouses, no significant sex or age differences were observed between the two groups of relatives (table 1).
The proportional distribution of types of relatives, however, was also non-different between the comparison groups.

Because the proband families tended to be slightly larger than spouse families, adjustment was made for the total number of relatives in the family when determining the familial risk of cancer. Case families were significantly more likely to contain at least one family member with any type of cancer $(\mathrm{OR}=1.82, \mathrm{P}<0.01)$. Each family was further classified according to the total number of cancers present among its menbers (none, one, two, three, four or more). Proband families were 1.67 times more likely to have one family member with cancer and 2.56 times more likely to have two family members with cancer than spouse families(table 2). For three cancers and four or more cancers, the relative risk increased to 3.50 and 5.91, respectively. Each risk other than the lastest estimate was

Table 3: Familial risk for developing cancer (non-lung cancer and lung cancer)among lung cancer case families and control families

\begin{tabular}{|c|c|c|c|c|c|}
\hline \multirow[b]{2}{*}{ Cancers (n.) } & \multicolumn{2}{|c|}{ Case } & \multicolumn{2}{|c|}{ Control } & \multirow[b]{2}{*}{$\mathrm{OR}^{\mathrm{b}}(95 \% \mathrm{Cl})$} \\
\hline & Families (no.) & Relatives $^{a}$ (no.) & Families (no.) & Relatives $^{a}$ (no.) & \\
\hline \multicolumn{6}{|c|}{ Non-lung cancer } \\
\hline 0 & 657 & 3,591 & 720 & 3,865 & \\
\hline 1 & 96 & 568 & 63 & 397 & $1.54(1.17-2.28)^{* *}$ \\
\hline 2 & 34 & 194 & 12 & 79 & $1.67(0.91-3.91)$ \\
\hline 3 & 11 & 83 & 4 & 28 & $2.11(1.02-7.98)^{*}$ \\
\hline $4+$ & 2 & 17 & 1 & 9 & $3.13(0.89-60.66)$ \\
\hline \multicolumn{6}{|l|}{ Lung cancer } \\
\hline 0 & 658 & 3629 & 706 & 3757 & \\
\hline 1 & 113 & 636 & 81 & 528 & $1.48(1.1 \mathrm{I}-2.02)^{*}$ \\
\hline 2 & 17 & 103 & 11 & 77 & $2.96(1.44-6.02)^{* *}$ \\
\hline 3 & 10 & 69 & 2 & 16 & $5.67(1.24-34.89)^{*}$ \\
\hline $4+$ & 2 & 16 & 0 & 0 & -- \\
\hline
\end{tabular}

$* \mathrm{p}<0.05 . * * \mathrm{p}<0.01$.

a Excludes probands and spouses. ${ }^{b}$ Represents familial risk of case families, not individual risk, adjusted for family size, total smoky coal exposure, number of person smoking and commune of residence. 
Table 4: Risk of cancer for relatives of lung cancer probands and controls

\begin{tabular}{llll}
\hline Relatives & Lung cancer ORb $(95 \% \mathrm{Cl})$ & Non-lung cancer OR ${ }^{\mathrm{b}}(95 \% \mathrm{Cl})$ & Any cancer ORb $(95 \% \mathrm{Cl})$ \\
\hline All relatives & & & $1.82(\mathrm{I} .52-2.02)^{* *}$ \\
Female relatives & $2.05(1.68-2.53)^{* *}$ & $1.4 \mathrm{I}(\mathrm{I} .08-2.13)^{*}$ & $2.45(1.84-3.20)^{* *}$ \\
Male relatives & $2.17(1.60-3.64)^{* *}$ & $2.00(1.26-3.01)^{* *}$ & $1.36(1.05-1.68)^{*}$ \\
Parents & $1.33(1.02-2.02)^{*}$ & $1.03(0.78-1.62)$ & $2.16(1.62-2.87)^{* *}$ \\
Fathers & $2.90(1.97-4.32)^{* *}$ & $1.52(1.01-2.30)^{*}$ & $1.80(1.20-2.69)^{* *}$ \\
Mothers & $2.17(1.21-3.86)^{*}$ & $1.30(0.86-2.27)$ & $3.12(2.03-4.66)^{* *}$ \\
Siblings & $2.78(1.23-5.12)^{* *}$ & $2.34(1.28-4.40)^{* *}$ & $1.51(1.28-1.80)^{* *}$ \\
Brothers & $1.65(1.19-2.18)^{*}$ & $1.31(0.97-2.01)^{*}$ & $1.09(0.82-1.49)$ \\
Sisters & $1.21(0.79-1.80)$ & $0.92(0.72-1.68)^{*}$ & $2.13(1.58-3.00)^{* *}$ \\
\hline
\end{tabular}

$* \mathrm{p}<0.05 * * \mathrm{p}<0.01$

a Excluded probands and spouses. ${ }^{b}$ OR adjusted for family size, commune of residence, birth oder, total smoky coal exposure, pack-years of smoking, COPD history, education, age, sex and years of cooking.

significant at the 0.01 level. The average age of those living family members with cancer, or deceased from cancer, is also presented. The differences are minimal.

To determine whether this excess risk was evident for cancers, we tabulated the total number of cancers in a family including lung cancer (International Classification of Diseases (ICD), 9 th $^{\text {th }}$ evision, code nos. 162.0-162.9) (table $3)$. After adjusting for confounder factors, the overall relative risk of one member with cancer in case families (OR 1.54) remained statistically significant. The odds ratios for separate categories also remained significant for families with three members with cancer. There was a trend of risk increased for families with more and more members with cancer. In addition, table 3 significantly shows the increased risk of lung cancer among relatives of lung cancer patients(OR 1.4-5.6, $\mathrm{P}<0.05)$, and the more number of relatives affected by lung cancer, the greater risk of lung cancer among the other relatives of lung cancer patients.

The results for the analyses that treated lung cancer, nonlung cancer and any cancer among relatives of probands as outcome variables are shown in table 4. Among the 4453 first-degree relatives of the probands, 185 (4.2\%) had a reported diagnosis of lung cancer, and 205 (4.6\%) had a diagnosis of a non-lung cancer. There were 109 $(2.5 \%)$ lung cancer cases and 103 (2.4\%) non-lung cancer cases among the 4378 first-degree relatives of the spouses. The strongest effects were for not only lung cancer in any female relatives (adjusted OR 2.17, 95\%CI 1.60-3.64) and mothers (adjusted OR 2.78, 95\%CI 1.23-5.12) and sisters (adjusted OR 2.03, 95\%CI 1.26-3.97), but also non-lung cancer in females and mothers (OR 2.00, 95\%CI 1.26-3.01, and OR 2.34, 95\%CI 1.28-4.40, respectively).

\section{Discussion}

In this study, we attempted to control for as many environmental risk factors as possible for both the probands and their relatives in order to understand better the cause of the observed family aggregation. These data demonstrate an increase risk of non-lung cancer and lung cancer specifically among first-degree relatives of lung cancer probands, and support the hypothesis that genetic factors play a role in the etiology of lung cancer. Tokuhata and Lilienfeld[2] provided the first epidemiologic evidence to support the hypothesis was provided, and reported a significantly increased risk of respiration cancer among relatives of lung cancer patients compared to age-, race-, and sex-matched controls. The risk for cancer in general, however, was not increased. The present authors[3] recently reports similar findings. Lynch et al. $[5,15]$ reported on the familial risk of cancer in relatives of lung cancer probands and probands with other smoking-related cancers (i.e. bladder, pancreas, oral cavity). They found no increased risk for lung cancer when considered separately. However, the risk for cancers of all anatomic sites was significantly increased among the relatives of lung cancer probands ( $\mathrm{p}$ $<0.001$ ). This increased risk was not evident for relatives of probands with other smoking-associated cancers, nor were the cancers themselves smoking-related. The authors conclude that the data are consistent with the hypothesis of an underlying susceptibility to malignancy in these families. Unlike Lynch et al.[5], the present study again reports an increased risk for lung cancer, and also notes an increased risk for cancer at several anatomic sites in relatives of lung cancer probands. Even after excluding persons with lung cancer and controlling for the assessed environmental exposures, a statistically significant excess risk of cancer was evident.

Our findings also suggest that female relatives (especially mothers) of lung cancer cases are at higher risk for lung cancer than male relatives. Previous studies have indicated that having a first-degree relative with lung cancer was significantly associated with lung cancer among non-smokers[3,6,16-18]. Why the apparently stronger association between lung cancer and lung cancer history in female rel- 
atives are unknown. Since certain smoky coal exposure and cooking habits have been implicated as an important risk factor for lung cancer among Chinese women[19]. Genetic factors might influence the susceptibility to environmental carcingens. Excess of 10 carcinogenic chemicals were identified in cooking and smoky coal fume and these shown to interact with one another[20,21] and these possible effects need to be evaluated further.

Findings of familial aggregation and statistical evidence for a major gene [22-24] have led to the search for highpenetrant, rare, single genes for lung cancer and low-penetrant, high-frequency, susceptibility genes for lung cancer[25]. Some of the most widely and recently studied polymorphic loci coding for phase I and II enzymes involved in the activation and conjugation of carcinogen are cytochrome P4501A1 (CYP1A1), glutathione S-transferase M1 (GSTM1), myeloperoxidase (MPO), and NAD(P)H: quinone oxidoreductase (NQO1)[25]. These genes encoding enzymes that are associated with carcinogen metabolism and DNA repair have been the focus of research into possible susceptibility genes for lung cancer and othe cancer. Furthermore, the recent findings show that the homozygous GSTP1 Ile105Val genetype was significantly under-represented in NSCLC compared with controls especially in females, and neither GSTM1 nor MPO genotypes affected the overall risk of NSCLC, and the MPO and CYP1A1 risk genotypes interacted to increase overall risk of NSCLC[26]. Multiple genes of modest effect interact to confer genomic-based susceptibility to lung cancer. It has been hypothesized that differences in susceptibility to carcinogens result from an individual's ability to form genotoxic intermediates, to detoxify these intermediates, and to repair damaged DNA. Polymorphisms in genes coding for the enzymes that drive these processes are likely candidate susceptibility genes. They could not only increase the lung cancer risk but also affect the risk of other cancers. Identifying and testing specific markers using a linkage analysis to confirm the gene involved in the development and progression of lung cancer, particularly to explore the interaction of gene-gene and gene-environment, should be a high future priority.

\section{Abbreviations}

ICD, international classification of diseases; COPD, chronic obstructive pulmonary disease; OR, odds ratio; $\mathrm{CI}$, confidence interval; GST, glutathione S-transferase; CYP, cytochrome P450; MPO, myeloperoxidase and NQO1, NAD(P)H: quinone oxidoreductase

\section{Competing interests}

The author(s) declare that they have no competing interests.

\section{Authors' contributions}

YJ designed the study and drafted the manuscript. YX carried out the statistical analysis. MX collected the data of lung cancer cases and controls. SX Participated in the design of the study and helped to draft the manuscript. All authors read and approved the final manuscript.

\section{Acknowledgements}

We thank those families who took part in the investigation. This work was supported by National Natural Science Foundation of China (NSFC) grants 30471427.

\section{References}

I. Cairns J: The cancer problem. Sci Am 1975, 233:64-78.

2. Tokuhata GK, Lilienfeld AM: Familial aggregation of lung cancer on humans. J Natl Cancer Inst 1963, 30:289-3I2.

3. Ooi WL, Elston RC, Chen VW, Baily-Wilson JE, Rothschild H: Increased familial risk for lung cancer. J Natl Cancer Inst 1986, 76:217-222.

4. Sellers TA, Ooi WL, Elston RC, Chen VW, Baily-Wilson JE, Rothschild $\mathrm{H}$ : Increased familial risk of non-lung cancer among relatives of lung cancer patients. Am J Epidemiol 1987, 126:237-246.

5. ynch HT, Kimberling WJ, Markvicks SE: Genetics and smokingassociated cancer. Cancer 1986, 57:1640-1646.

6. Jonsson S, Thorsteinsdottir U, Gudbhartsson DF, Jonsson HH, Kristjansson K, Arnason S, Guduason V, Isaksson HJ, Gulcher JR, Amundadottir LT, Kong A, Stefansson K: Familial risk of lung carcinoma in the Icelandic population. JAMA 2004, 292:2977-2983.

7. Horowitz RI, Smaldone LF, Viscoli CM: An ecogenetics hypothesis for lung cancer in women. Arch Intern Med 1988, 148:2609-26I2.

8. Khoury MJ, Beaty TH, Liang KY: Can familial aggregation of disease by explained by familial aggregation of environmental risk factors? Am J Epidemiol 1988, 127:674-683.

9. Ahsan H, Thomas DC: Lung cancer etiology: independent and joint effects of genetics, tobacco, and arsentic. JAMA 2004, 29:3026-3029.

10. Warthin AS: Heredity with reference to carcinoma as show by the study of the cases examined in the pathological laboratory of the University Michigan, 1895-1913. Arch Intern Med 1913, 1 2:546-555.

II. Lynch HT, Krush AJ: Differential diagnosis of the cancer family syndrome. Surg Gynecol Obstet 1973, I36:22 I-224.

12. Schneider NR: Familial aggregation of cancer. In Genetics in clinical oncology Edited by: Chaganti RSK, German J. New York: Oxford University Press; 1985:133-145.

13. Woolf B: On estimating the relation between blood group and disease. Ann Hum Genet 1954, 19:25I-254.

14. SAS Institute. Inc: SAS/STAT software: changed and enhancements through release 6.12. Cary, NC: SAS Institute, Inc; 1997.

15. Etzel CJ, Amos Cl, spitz MR: Risk for smoking-related cancer among relatives of lung cancer patients. Cancer Res 2003, 63:853|-8535.

16. Schwartz AG, Yang P, Swanson GM: Familial risk of lung cancer among non-smokers and their relatives. Am J Epidemiol I996, 144:554-562.

17. Wu AH, Fontham ET, Reynolds P, Greenberg RS, Buffler P, Liff J, Boyd $\mathrm{P}$, Correa P: Family history of cancer and risk of lung cancer among lifetime non-smoking women in the United States. Am J Epidemiol 1996, 143:535-542.

18. Shaw GL, Falk RT, Pickle LW, Mason TJ, Buffler PA: Lung cancer risk associated with cancers in relatives. J Clin Epidemiol I99I, 44:429-437.

19. Lan Q, Chen W, Chen H, He XZ: Risk factors for lung cancer in non-smokers in Xuanwei County of China. Biomed Environ Sci 1993, 6:112-118.

20. Chiang TA, Wu PF, Ko TC, Lee H: Genotoxicity of fumes from heated cooking oils produced in Taiwan. Environ Res 1999 , 80:122-126.

21. Mumford JL, Helme CT, Lee XM, Seidenberg J, Nesnow S: Mouse skin tumorigenicity studies of indoor coal and wood combustion emissions from homes of residents in Xuan Wei, China 
with high lung cancer mortality. Carcinogenesis (Lond) 1990, II:397-403.

22. Jin YT, Xu YC, Yang RD, Xu CW, He XZ: Familial aggregation of lung cancer in a high incidence area in China. Brit J cancer 2005, 92:1321-1325

23. Sellers TA, Ooi WL, Elston RC, Chen VW: Increased familial risk for non-lung cancer among relatives of lung cancer patients. Am J Epidemiol 1987, 1 26:237-246.

24. Wu PF, Lee CH, Wang MJ, Goggins WB, Chiang TA, Huang MS, Ko YC: Cancer aggregation and complex segregation analysis of families with female non-smoking lung cancer probands in Taiwan. European Journal of Cancer 2004, 40:260-266.

25. Schwartz G: Genetic predisposition to lung cancer. Chest 2004, I 25(5_suppl):86S-89S.

26. Larsen JE, Colosimo ML, Yang IA, Bowman R, Zimmerman PV, Fong KM: CYPIAI Ile 462 and MPO G-463A interact to increase risk of adenocarcinoma but not squamous cell carcinoma of the lung. Carcinogenesis in press. 2005, Sep 29

\section{Pre-publication history}

The pre-publication history for this paper can be accessed here:

http://www.biomedcentral.com/1471-2407/5/146/pre

pub

Publish with Bio Med Central and every scientist can read your work free of charge

"BioMed Central will be the most significant development for disseminating the results of biomedical research in our lifetime. "

Sir Paul Nurse, Cancer Research UK

Your research papers will be:

- available free of charge to the entire biomedical community

- peer reviewed and published immediately upon acceptance

- cited in PubMed and archived on PubMed Central

- yours - you keep the copyright

Submit your manuscript here:

http://www.biomedcentral.com/info/publishing_adv.asp 